Jap. J. M. Sc. \& Biol., 12, 23-31, 1960

\title{
A STABILIZING EFFECT OF HEMOGLOBIN ON THE PNEUMOCOCCUS TRANSFORMATION
}

\author{
Yukito MASAMUNE, MiHoko ABE AND DEN'ichi MIZUNO \\ Department of Chemistry, National Institute of Health, Tokyo
}

(Received: April 15th, 1960)

In experiments of Pneumococcus transformation, several media have been devised in an attempt to improve the reproducibility of results ever since the in vitro reaction was first carried out by Dawson (1931). It has been recognized that the occurrence of the in vitro reaction requires some environmental factors, in addition to the nutrients necessary for the initiation and maintenance of cell growth (McCarty et al., 1946). Rabbit serum or human serous fluids provided such factors in many cases (E-Taylor, 1949; Austrian, 1952). Hotchkiss and E-Taylor (1951) pointed out that bovine albumin could substitute the factors. However even in the presence of these factors, a reproducible and stable result was not necessarily secured in the Pneumococcus transformation. In order to obtain a constant and regular result in this reaction, it will be necessary to supply a better qualified medium and appropriate factor(s). At the same time, elucidation of the nature of such factor(s), if any, will be significant to an understanding of the mechanism of the transformation reaction.

During the course of experiments performed in our laboratory on Pneumococcus transformation from SM sensitive to resistant cells, using heart infusion Neopepton broth as a basic medium, it was found that an addition of albumin and of horse blood hemolysate gave good results, while irregular results were obtained with the addition of albumin only. The experiments performed to ascertain the nature of the substance(s) in the hemolysate will be presented below.

\section{MATERIALS AND METHODS}

Strains: Diplococcus pneumoniae, RSt5b (SM resistant, DNA donor strain) and R19 (recipient strain) were the same as in the previous report (Abe and Mizuno, 1959).

Preparation of DNA from the SM resistant strain, and transformation reaction: The same technique as described before was followed (Abe and Mizuno, 1959). The assay of transformants was always done in agar plates containing SM $(150 \mu \mathrm{g} / \mathrm{cc}) 100$ minutes after the addition of DNA.

Medium: The basic medium contained per liter Heart infusion broth 'Difco' $10 \mathrm{~g}$, Neopepton 'Difco' $10 \mathrm{~g}$ and $\mathrm{Na}_{2} \mathrm{HPO}_{4} \cdot 2 \mathrm{H}_{2} \mathrm{O} 2.5 \mathrm{~g}$, and was brought to $\mathrm{pH} 7.6-7.8$ with a $\mathrm{NaOH}$ solution. Nutrient broth for cultivation of DNA donor cells, solid medium for the counting of SM resistant transformants and of survival cells were the same as described previously (Abe and Mizuno, 1959). Bovine albumin (Armour Lab.) was added to the basic medium for the transformation reaction to make the final concentration of $0.2 \%$. This is called 'transformation medium'.

* Aided in part by a grant of the Hôan-sha Foundation.

** The following abbreviations will be used: Streptomysin (SM); Deoxyribonucleic acid (DNA); Brom phenol blue (BPB).

正宗行人・阿部美穂子・水野伝一（国立予防衛生研究所化学部） 
Preparation of hemolysate: Fresh defibrinated horse blood was centrifuged, and the blood cells precipitated were added [with distilled water to 2 times the original volume of blood. The lysed cells were centrifuged at $3,000 \mathrm{rpm}$ for $10 \mathrm{~min}$. The supernatant will be called 'hemolysate'. The hemolysate was kept frozen and added to the medium prior to use. The concentration of the hemolysate in the medium will be shown in $\mathrm{v} / \mathrm{v} \%$.

Preparation of hemin, oxyhemoglobin and methemoglobin: Hemin was prepared from horse blood as described by Akabori (1949). Oxyhemoglobin and methemoglobin were prepared by the following method (Egami et al., 1953).

Oxyhemoglobin: Fresh horse blood cells were washed several times with saline, and added with an equal volume of distilled water, which was followed by an addition of half a volume of ether. After centrifugation of the lysed mixture, the water layer containing hemoglobin was dialysed in a cellophan bag against distilled water. The hemoglobin was crystallized within the bag. It was collected and dissolved in $\mathrm{M} / 15 \mathrm{Na}_{2} \mathrm{HPO}_{4}$ solution, and its extinction at $575 \mathrm{~m} \mu$ was adjusted to that of hemolysate. This preparation was used as 'crystalline oxyhemoglobin'.

Methemoglobin: A few drops of $5 \%$ ferricyanide solution were added to the crystalline oxyhemoglobin solution to convert it to methemoglobin. The excess ferricyanide was dialysed off against water. The dialysed solution was used as 'methemoglobin'.

\section{RESULTS}

\section{Effect of the Hemolysate Added to the Basic Medium}

The basic medium mentioned above could not support the growth of cells without treatment by charcoal or addition of serum or of albumin. The charcoal treatment (Tolmach, 1957) of the medium was not adopted to obtain satisfactory, reproducible results, because of the difficulty of regulating the conditions. As shown below the cells grown in the transformation medium were competent to the reaction, though within a limited period and at a low rate. We added the hemolysate to this medium. The hemolysate added alone in 0.5 to $1 \%$ in the basic medium was able to support the growth of cells but could not support the transformation reaction. The effect of the hemolysate added to the transformation medium in 0.01 to $1 \%$ is indicated in Table 1 . The hemolysate in concentrations of 0.1 to $1 \%$ promoted the reaction.

Table 1. Effect of the hemolysate to support Pneumococcus transformation in the 'transformation medium'*

\begin{tabular}{llccc}
\hline & $\begin{array}{c}\text { Supplement to the } \\
\text { transformation medium* }\end{array}$ & Viable cells/cc & SM resistants/cc & $\begin{array}{c}\text { II } \\
\text { Transformation } \\
\text { rate }\end{array}$ \\
\hline Exp. 1 & None & $1.4 \times 10^{7}$ & $<10$ & - \\
& Hemolysate 1\% & $2.2 \times 10^{7}$ & $1.8 \times 10^{4}$ & $7.9 \times 10^{-4}$ \\
& Hemolysate 0.1\% & $1.5 \times 10^{7}$ & $9.5 \times 10^{3}$ & $6.2 \times 10^{-4}$ \\
& Hemolysate 0.01\% & $2.1 \times 10^{7}$ & $1.0 \times 10^{1}$ & $4.8 \times 10^{-7}$ \\
& None & $2.2 \times 10^{7}$ & $<10$ & - \\
& Hemolysate 1\% & $2.3 \times 10^{7}$ & $4.9 \times 10^{4}$ & $2.1 \times 10^{-3}$ \\
& Hemolysate 0.1\% & $2.4 \times 10^{7}$ & $1.7 \times 10^{4}$ & $7.0 \times 10^{-4}$ \\
& Hemolysate $0.01 \%$ & $1.9 \times 10^{7}$ & $<10$ & - \\
\hline
\end{tabular}

* The transformation medium is the basic medium added with $0.2 \%$ albumin.

The basic medium contained heart infusion 'Difco' $10 \mathrm{~g}$, Neopepton 'Difco' $10 \mathrm{~g}$ and $\mathrm{Na}_{2} \mathrm{HPO}_{4} \cdot 2 \mathrm{H}_{2} \mathrm{O} 2.5 \mathrm{~g}$ in $1 l$ and was adjusted to $\mathrm{pH} 7.6-7.8$ with $\mathrm{NaOH}$. 
Table 2. Effect of the supernatant* of the hemolysate to support Pneumococcus transformation in the transformation medium m* $^{*}$

\begin{tabular}{llccc}
\hline & $\begin{array}{c}\text { Supplement to the } \\
\text { transformation medium }^{* *}\end{array}$ & $\begin{array}{c}\text { I } \\
\text { Viable cells/cc }\end{array}$ & $\begin{array}{c}\text { II } \\
\text { SM resistants/cc }\end{array}$ & $\begin{array}{c}\text { II/I } \\
\text { Transformation } \\
\text { rate }\end{array}$ \\
\hline Exp. 1 & None & $9.8 \times 10^{6}$ & $<10$ & - \\
& Hemolysate 1\% & $1.2 \times 10^{7}$ & $6.0 \times 10^{4}$ & $5.1 \times 10^{-3}$ \\
& Supernatant 1\% & $9.1 \times 10^{6}$ & $5.3 \times 10^{4}$ & $5.8 \times 10^{-3}$ \\
Exp. 2 & None & $1.2 \times 10^{7}$ & $1.2 \times 10^{4}$ & $1.0 \times 10^{-3}$ \\
& Hemolysate 1\% & $1.6 \times 10^{7}$ & $2.6 \times 10^{5}$ & $1.6 \times 10^{-2}$ \\
& Supernatant 1\% & $2.3 \times 10^{7}$ & $2.4 \times 10^{5}$ & $1.1 \times 10^{-2}$ \\
\hline
\end{tabular}

* The supernatant was obtained by centrifugation of the hemolysate at $100,000 \mathrm{~g}$, for $40 \mathrm{~min}$.

** See Table 1.

\section{Ultracentrifuge Fractionation of the Hemolysate}

In order to know what component(s) of the hemolysate would show the promoting effect on the transformation reaction, the hemolysate was fractionated by ultracentrifugation. The hemolysate was centrifuged at $100,000 \mathrm{~g}$ for 40 minutes to isolate a supernatant from precipitable particles. The activity of the supernatant, as is presented in Table 2, was almost comparable to that of control (hemolysate), showing the presence of the active principle in the soluble fraction.

\section{Dialysis of the Hemolysate}

The effect of the dialysed hemolysate is shown in Table 3. The hemolysate was dialysed in a cellophan bag against distilled water in a cold-room for 24 hours. The

Table 3. Effect of the dialysed hemolysate* to support Pneumococcus transformation in the transformation medium**

\begin{tabular}{llccc}
\hline & $\begin{array}{c}\text { Supplement to the } \\
\text { transformation medium } * *\end{array}$ & $\begin{array}{c}\text { I } \\
\text { Viable cells/cc }\end{array}$ & $\begin{array}{c}\text { II } \\
\text { SM resistants/cc }\end{array}$ & $\begin{array}{c}\text { Transformation } \\
\text { rate }\end{array}$ \\
\hline Exp. 1 & None & $3.3 \times 10^{6}$ & $3.0 \times 10^{3}$ & $9.1 \times 10^{-6}$ \\
& Hemolysate 1\% & $5.3 \times 10^{6}$ & $1.9 \times 10^{5}$ & $3.6 \times 10^{-2}$ \\
& Dialysed hemolysate 1\% & $6.9 \times 10^{6}$ & $4.4 \times 10^{4}$ & $6.4 \times 10^{-3}$ \\
Exp. 2 & None & $4.8 \times 10^{6}$ & $3.0 \times 10^{3}$ & $6.7 \times 10^{-4}$ \\
& Hemolysate 1\% & $8.9 \times 10^{6}$ & $9.9 \times 10^{4}$ & $1.1 \times 10^{-2}$ \\
& Dialysed hemolysate 1\% & $1.1 \times 10^{7}$ & $8.3 \times 10^{4}$ & $7.6 \times 10^{-3}$ \\
Exp. 3 & None & $2.7 \times 10^{6}$ & $6.0 \times 10^{2}$ & $2.2 \times 10^{-4}$ \\
& Hemolysate 1\% & $4.6 \times 10^{6}$ & $6.0 \times 10^{3}$ & $1.3 \times 10^{-3}$ \\
& Dialysed hemolysate 1\% & $6.0 \times 10^{6}$ & $8.0 \times 10^{3}$ & $1.3 \times 10^{-3}$ \\
\hline
\end{tabular}

* The hemolysate was dialysed in a cellophan bag against distilled water in a cold room for $24 \mathrm{hrs}$.

** See Table 1 . 
Table 4. Effect of the dialysable fraction of hemolysate to support Pneumococcus transformation in the transformation medium**

\begin{tabular}{llccc}
\hline & $\begin{array}{c}\text { Supplement to the } \\
\text { transformation medium** }\end{array}$ & $\begin{array}{c}\text { I } \\
\text { Viable } \\
\text { cells/cc }\end{array}$ & $\begin{array}{c}\text { II } \\
\text { SM } \\
\text { resistants/cc }\end{array}$ & $\begin{array}{c}\text { II/I } \\
\text { Transformation } \\
\text { rate }\end{array}$ \\
\hline \multirow{2}{*}{ Exp. 1 1} & a. None & $2.1 \times 10^{7}$ & $<10$ & - \\
& b. Hemolysate 1\% & $2.0 \times 10^{7}$ & $2.3 \times 10^{4}$ & $1.2 \times 10^{-3}$ \\
& c. Dialysed hemolysate 1\% & $2.2 \times 10^{7}$ & $1.2 \times 10^{3}$ & $5.5 \times 10^{-4}$ \\
& d. Dialysable fraction 1\% & $2.1 \times 10^{7}$ & $8.0 \times 10^{1}$ & $3.8 \times 10^{-6}$ \\
& e. c plus d 1\% each & $2.6 \times 10^{7}$ & $2.6 \times 10^{3}$ & $1.0 \times 10^{-3}$ \\
Exp. 2 & a. None & $9.8 \times 10^{6}$ & $<10$ & - \\
& b. Hemolysate 1\% & $1.2 \times 10^{7}$ & $6.0 \times 10^{4}$ & $5.1 \times 10^{-3}$ \\
& c. Dialysed hemolysate 1\% & $1.1 \times 10^{7}$ & $1.8 \times 10^{4}$ & $1.7 \times 10^{-3}$ \\
& d. Dialysable fraction 1\% & $1.1 \times 10^{7}$ & $1.4 \times 10^{2}$ & $1.3 \times 10^{-5}$ \\
& e. c plus d 1\% each & $1.3 \times 10^{7}$ & $2.8 \times 10^{4}$ & $2.2 \times 10^{-3}$ \\
f. Oxyhemoglobin 1\% & $1.3 \times 10^{7}$ & $1.4 \times 10^{4}$ & $1.0 \times 10^{-3}$ \\
& g. f plus d 1\% each & $1.1 \times 10^{7}$ & $5.3 \times 10^{4}$ & $4.9 \times 10^{-3}$ \\
\hline
\end{tabular}

* The dialysed fraction was evaporated to the initial volume of the hemolysate by a flushing evaporator at $c a .35^{\circ} \mathrm{C}$.

** See Table 1 .

Table 5. F-test of mean values of transformation rates in the medium supplemented with the hemolysate fractions

\begin{tabular}{|c|c|c|c|c|c|c|c|}
\hline \multirow{2}{*}{$\begin{array}{l}\text { Supplement to the } \\
\text { transformation medium* }\end{array}$} & \multicolumn{5}{|c|}{ Transformation rate $\left(\frac{\mathrm{SM} \text { resistants }}{\text { viable cells }}\right)$} & \multirow{2}{*}{$\begin{array}{c}\text { Mean } \\
\mathrm{X}_{\mathrm{i}}\end{array}$} & \multirow{2}{*}{$\begin{array}{c}\text { Variance } \\
\mathrm{s}_{\mathrm{i}}^{2}\end{array}$} \\
\hline & Exp. 1 & Exp. 2 & Exp. 3 & Exp. 4 & Exp. 5 & & \\
\hline a. Hemolysate & $1.4 \times 10^{-3}$ & $1.3 \times 10^{-8}$ & $2.7 \times 10^{-8}$ & $1.6 \times 10^{-3}$ & $1.6 \times 10^{-3}$ & $1.7 \times 10^{-8}$ & $0.25 \times 10^{-6}$ \\
\hline b. Dialysed hemolysate & $<10^{-8}$ & $2.7 \times 10^{-8}$ & $0.55 \times 10^{-8}$ & $1.9 \times 10^{-3}$ & $0.4 \times 10^{-3}$ & $1.1 \times 10^{-8}$ & $1.04 \times 10^{-8}$ \\
\hline c. b plus dialysable fraction & $2.9 \times 10^{-8}$ & $1.5 \times 10^{-8}$ & $2.2 \times 10^{-3}$ & $1.6 \times 10^{-8}$ & $1.1 \times 10^{-8}$ & $1.9 \times 10^{-3}$ & $0.40 \times 10^{-6}$ \\
\hline
\end{tabular}

The differences among the variances $\left(\mathrm{S}_{\dot{i}}^{2}\right)$ of (a) (b) (c) have no significance at $5 \%$ level. The mean values $\left(\mathrm{X}_{\mathrm{i}}\right)$ of them also have no significant differences at $5 \%$ level.

* See Table 1.

dialysed hemolysate was added to the transformation medium in the concentration of $1 \%$. Although the dialysed hemolysate showed a lower activity than the original hemolysate in most cases, a significant promotive effect of the dialysed hemolysate was recognized as compared with that exerted by the addition of albumin only.

The dialysable fraction was evaporated to the initial volume of the hemolysate by a flushing evaporator at about $35^{\circ} \mathrm{C}$. The effect of this solution which was added to the transformation medium in the concentration of $1 \%$ is indicated in Table 4 . The dialysable fraction had little effect when added alone to the transformation medium. But when added together with the dialysed hemolysate, the results seemed to suggest 
the presence of some factor(s) in the dialysable fraction which could restore, to some extent, the lowered activity of the non-dialysable fraction (Table 4). Therefore, we tried to analyse statistically the significance of the differences between the transformation rate obtained by the medium with the non-dialysable fraction only and that with both the dialysable and non-dialysable fractions. The results showed that we could not expect the presence of any factor(s) in the dialysable fraction which might have an additive effect (Table 5).

\section{Heat Stability}

Fig. 1 represents the effect of heat on the activity of the hemolysate to support the transformation reaction. The hemolysate was heated at each temperature indicated for

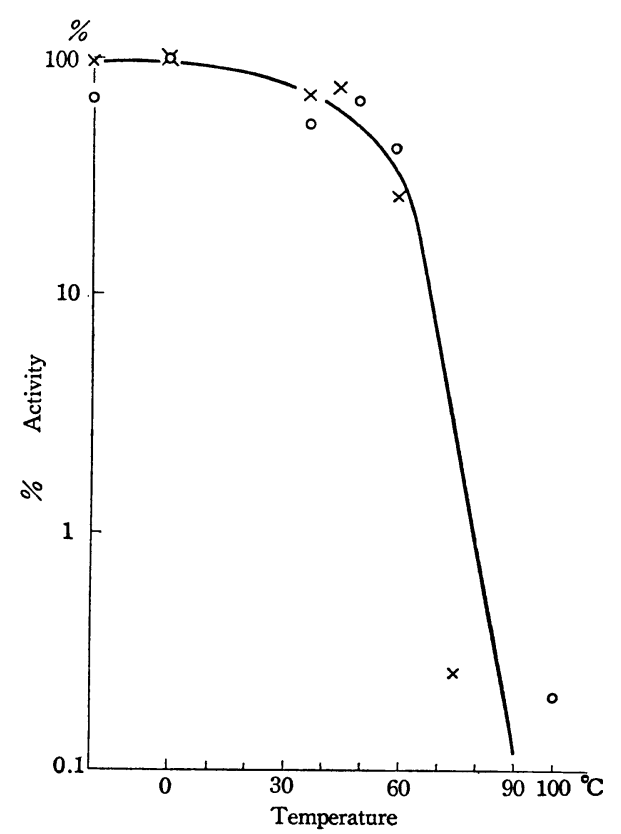

Fig. 1. Heat stability of the hemolysate and the oxyhemoglobin.

The hemolysate $(O)$ or the oxyhemoglobin $(x)$ was heated at each temperature indicated for 1 hour. The activity was expressed by transformation rate $\left(\frac{\mathrm{SM} \text { resistant/cc }}{\text { viable cells/cc }}\right)$.

The ordinate indicates the activity of the heated sample as percentage of the original hemolysate; the abscissa indicates the temperature where the sample was heated.

60 minutes, and each heated hemolysate was added in the same concentration as that of the non-heated hemolysate. The curve of inactivation of the hemolysate dropped at around $60^{\circ} \mathrm{C}$. The activity was lost completely at $100^{\circ} \mathrm{C}$. Hemin was prepared from horse blood and added to the medium, but it did not reveal any activity to support the transformation reaction. 


\section{Electrophoretic Separation of the Dialysed Hemolysate}

The dialysed hemolysate was separated electrophoretically in the following conditions: $\mathrm{M} / 15$ phosphate buffer, $\mathrm{pH} 8.0$, Whateman No.1 filter paper, strip $4 \mathrm{~cm} \times 30 \mathrm{~cm}, 0.3 \mathrm{~mA}$ per $\mathrm{cm}^{2}, 300 \mathrm{~V}$, for 23 hours, in a cold room. The paper was stained with BPB. As is illustrated in Fig. 2, a densitometrically single peak was obtained.

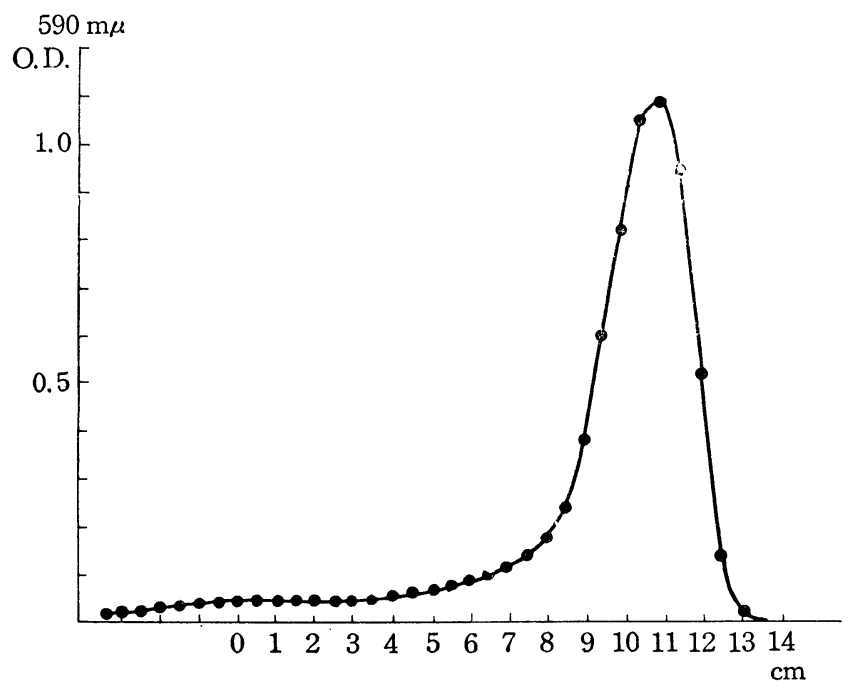

Fig. 2. Electrophoretic protein pattern of the dialysed hemolysate.

\section{Effect of Hemoglobin}

It seems likely, from the results described above, that the active component of the hemolysate is a soluble protein, probably oxyhemoglobin which is a principal component of erythrocyte. The effect of the crystalline oxyhemoglobin to support the transformation reaction is presented in Table 6 . The crystalline oxyhemoglobin showed, sometimes, a lower activity than the control hemolysate, but it was definitely promotive to the reaction as compared with the control employing the transformation medium only. The heat stability of the oxyhemoglobin was the same as that of the hemolysate. Therefore, it seems likely that the effect of the non-dialysable fraction depends essentially on the presence of oxyhemoglobin therein.

\section{Effect of Methemoglobin}

A question arose as to whether or not the hemoglobin had to be an oxygenated form i.e. oxyhemoglobin, to play an essential role in the transformation reaction.

Methemoglobin was tested in comparison with oxyhemoglobin. The results are cited in Table 7. The methemoglobin showed a lesser effect than oxyhemoglobin in a comparable concentration.

\section{Appearance and Maintenance of Cell Competency in the Presence of Supplements for the Basic Medium.}

For the comparison of the effect of supplements on the basic medium, the following 
Table 6. Effect of the crystalline oxyhemoglobin* to support Pneumococcus transformation in the transformation medium**

\begin{tabular}{|c|c|c|c|c|}
\hline & $\begin{array}{l}\text { Supplement to the } \\
\text { transformation medium }\end{array}$ & $\begin{array}{c}\text { I } \\
\text { Viable } \\
\text { cells/cc }\end{array}$ & $\underset{\text { resistants/cc }}{\mathrm{II}}$ & $\underset{\substack{\text { II } / \mathrm{I} \\
\text { rate }}}{\text { Transformation }}$ \\
\hline \multirow[t]{4}{*}{ Exp. 1} & None & $4.8 \times 10^{6}$ & $3.0 \times 10^{3}$ & $6.7 \times 10^{-4}$ \\
\hline & Hemolysate $1 \%$ & $8.9 \times 10^{6}$ & $9.9 \times 10^{4}$ & $1.1 \times 10^{-2}$ \\
\hline & $\begin{array}{l}\text { Crystalline oxy- } \\
\text { hemoglobin } 1 \% * * *\end{array}$ & $1.4 \times 10^{7}$ & $7.0 \times 10^{4}$ & $5.1 \times 10^{-3}$ \\
\hline & Dialysed hemolysate $1 \%$ & $1.1 \times 10^{7}$ & $8.3 \times 10^{4}$ & $7.6 \times 10^{-3}$ \\
\hline \multirow[t]{4}{*}{ Exp. 2} & None & $3.3 \times 10^{6}$ & $3.0 \times 10^{1}$ & $9.1 \times 10^{-6}$ \\
\hline & Hemolysate & $9.8 \times 10^{6}$ & $9.2 \times 10^{4}$ & $9.5 \times 10^{-3}$ \\
\hline & $\begin{array}{l}\text { Crystalline oxy- } \\
\text { hemoglobin } 1 \%\end{array}$ & $1.1 \times 10^{7}$ & $3.9 \times 10^{3}$ & $4.5 \times 10^{-3}$ \\
\hline & Dialysed hemolysate $1 \%$ & $1.4 \times 10^{7}$ & $4.4 \times 10^{3}$ & $3.2 \times 10^{-3}$ \\
\hline
\end{tabular}

* The hemoglobin was crystallized from horse blood cells.

** See Table 1 .

*** The concentration of hemoglobin was adjusted by the extinction at $575 \mathrm{~m} \mu$, to that of the hemolysate. This preparation was called crystalline oxyhemoglobin.

Table 7. Effect of the methemoglobin* to support Pneumococcus transformation in the transformation medium**

\begin{tabular}{llccc}
\hline & \multicolumn{1}{c}{$\begin{array}{c}\text { Supplement to the } \\
\text { transformation medium }\end{array}$} & $\begin{array}{c}\text { I } \\
\text { Viable } \\
\text { cells/cc }\end{array}$ & $\begin{array}{c}\text { II } \\
\text { SM } \\
\text { resistants/cc }\end{array}$ & $\begin{array}{c}\text { II/I } \\
\text { Transformation } \\
\text { rate }\end{array}$ \\
\hline Exp. 1 & a. Hemolysate 1\% & $1.6 \times 10^{7}$ & $6.8 \times 10^{4}$ & $4.3 \times 10^{-3}$ \\
& b. Methemoglobin 1\% & $1.5 \times 10^{7}$ & $1.4 \times 10^{2}$ & $9.7 \times 10^{-4}$ \\
& c. Dialysable fraction 1\% & $1.4 \times 10^{7}$ & $<10$ & - \\
& d. b plus c, 1\% each & $2.0 \times 10^{7}$ & $3.4 \times 10^{4}$ & $1.7 \times 10^{-3}$ \\
Exp. 2 & a. Hemolysate 1\% & $2.2 \times 10^{7}$ & $1.8 \times 10^{4}$ & $8.1 \times 10^{-4}$ \\
& b. Methemoglobin 1\% & $2.2 \times 10^{7}$ & $3.0 \times 10^{2}$ & $1.4 \times 10^{-5}$ \\
& c. Dialysable fraction 1\% & $1.9 \times 10^{7}$ & $<10$ & - \\
& d. b plus c, 1\% each & $2.4 \times 10^{7}$ & $8.6 \times 10^{3}$ & $3.6 \times 10^{-4}$ \\
\hline
\end{tabular}

* Methemoglobin was prepared by oxydation of oxyhemoglobin with ferricyanide.

** See Table 1 .

was used as such : albumin $0.2 \%$; albumin $0.2 \%$ and hemolysate $1 \%$; albumin $0.2 \%$ and crystalline oxyhemoglobin 1\%. Each medium containing either one of the supplements was inoculated with an equal number of preincubated cells, and the cells grown in each medium were tested for their competency to the transformation reaction at the time interval indicated. The total survival cell number was also counted. The results are recorded in Fig. 3. It was indicated that the effect to support the growth of cells, expressed by total survival cell count, was the same among all the three supplements. 
The cell competency was almost equal in the medium supplemented with either the hemolysate or hemoglobin. The cell competency in both the media reached the maximum level at around 4 hours after the inoculation, and remained on that level even 6 hours after the inoculation. On the other hand, in the medium added with albumin only, the cells showed a considerably high competency at an early phase, though it was lower than in the case of albumin plus the hemolysate. However, the competency in this case did not last so long and eventually was lost rapidly. This fact may account for the irregularity of the transformation rate in the medium supplemented with albumin only, as experienced so far in many experiments.

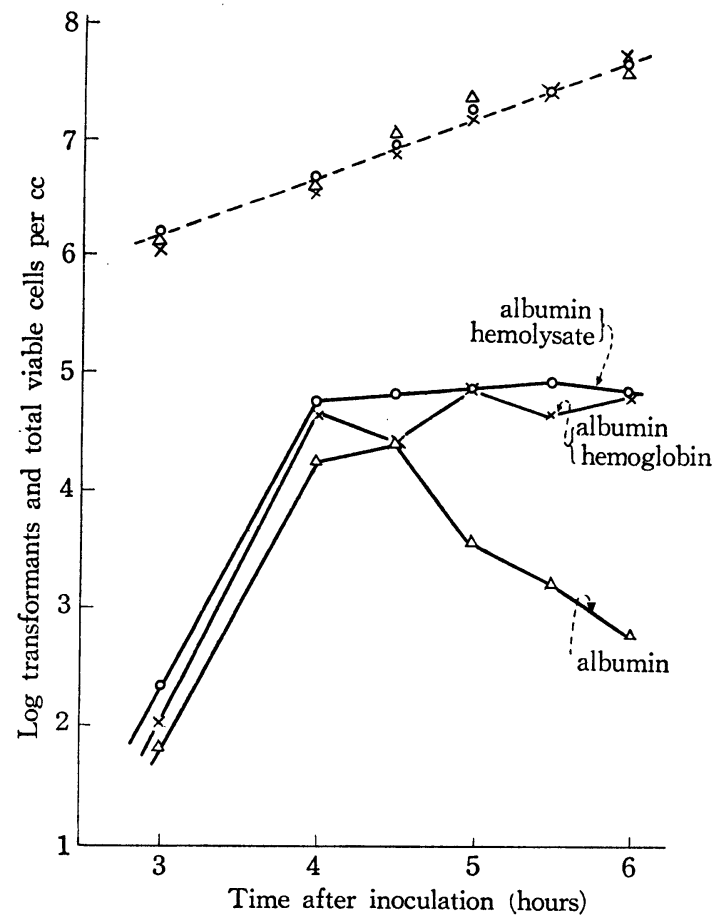

Fig. 3. Cell competency in the culture grown in the basic medium containing supplements.

The basic medium (see Table 1) was supplemented with albumin $0.2 \%$ $(\triangle)$, albumin and the hemolysate $(\bigcirc)$ or albumin and hemoglobin $(X)$. Total survival cell count: - - - - . Transformant count :

\section{DISCUSSION}

The necessity of serous factor in the transformation of various bacterial species and the effectiveness of serum albumin on the Pneumococcus transformation have been recognized. In our case, the basic medium containing heart infusion, Neopepton and phosphate could not support good growth of this organism. An addition of albumin or treatment by charcoal was sufficient to grow cells but was not able to support the transformation reaction. These treatments may behave in favor of removing some inhibitory substance $(\mathrm{s})$, probably some free fatty acids (Pollock, 1949) contained in the medium. Besides, a 
specific role of albumin to support the transformation reaction was also shown in our case. An additive and, probably, stabilizing effect of the hemolysate or oxyhemoglobin added to the basic medium containing albumin was evident in the above experiment. It is very profitable for the study of this reaction that the cell competency to transformation reaction can be kept constant during a broad growth phase in the medium supplemented with the hemolysate or with the oxyhemoglobin (Fig. 3). It is uncertain whether hemoglobin (or hemolysate) is an additive sensitizer to albumin in the transformation reaction, or a substance acting as a factor maintaining the competency of cells. It is of interest to know the mechanism of the specific role of hemoglobin in the medium for the transformation reaction.

It seems likely that the oxygen in the oxyhemoglobin preparation may play a minor part in the activity of oxyhemoglobin, since we could not get any good results when we aerated the culture before the DNA treatment.

\section{SUMMARY}

1. The addition of horse blood hemolysate to the medium for Pneumococcus transformation, in addition to albumin, showed a promotive effect in supporting the reaction.

2. The hemolysate added to the medium of Pneumococcus transformation elongated the time duration of the state where the cells were competent to the transformation as compared with the case in which the basic medium was supplemented with albumin only.

3. It was established that the hemolysate could be replaced by the crystalline oxyhemoglobin retaining the effect.

\section{REFERENCES}

ABE, M. \& Mizuno, D. (1959): A contribution to the knowledge of Pneumococcus transformation during the period between the incorporation of deoxyribonucleic acid and the appearance of streptomycin resistance. Biochim. Biophys. Acta, 32, 464-469.

AKABORI, S. ed. (1959): [The preparation method of biochemical reagent.] p. 265. Sogen-sha (text in Japanese).

AUSTRIAN, R. (1952): Bacterial transformation reaction. Bact. Rev., 16, 31-50.

DAwson, M. H. \& SIA, R. H. P. (1931): In vitro transformation of Pneumococcal types. I. A technique for inducing transformation of pneumococcal types in vitro. J. Exper. Med., 54 681-699.

EGAMI, F. et al. ed. (1952) : [Standard Biochemical Experiment]. pp. 112-120, Bunkyo-do (text in Japanese).

EPHRUSSI-TAYLOR, H. (1949): Additive effect of certain transformating agents from some variants of Pneumococcus. J. Exper. Med., 89, 399-424.

Hotchiss, R. D. \& EPHRUSSI-TAYLOR, H. (1951): Use of serum albumin as source of serum factor in pneumococcal transformation. Fed. Proc., 10, 200.

LERMAN, L. S. \& TOLMACH, L. J. (1957): Genetic transformation. I. Cellular incorporation of DNA accompanying transformation in Pneumococcus. Biochim. Biophys. Acta, 26, 68-82.

MCCARTy, M. Ephaussi-TAYloR, H. \& Avery, O. T. (1946) : Biochemical studies of environmental factors essential in transformation of pneumococcal types. Cold Spring Harbor Symp. Quant. Biol., XI, 177-183.

POLLOCK, M. R. (1949): The effect of long-chain fatty acids on the growth of Haemophillus pertussis and other organisms. Symp. Soc. Exper. Biol., 3, 217-232. 